\title{
An equivalence study comparing nitrous oxide and oxygen with low-dose sevoflurane and oxygen as inhalation sedation agents in dentistry for adults
}

IN BRIEF

- Improves knowledge of the efficacy of low-dose sevoflurane and oxygen as an inhalation sedation agent.

- Provides evidence for a viable alternative to nitrous oxide and oxygen.

- Opens the way for further research into higher, sub-MAC, use of sevoflurane and oxygen.

\author{
M. Allen ${ }^{* 1}$ and S. Thompson ${ }^{2}$
}

\begin{abstract}
Objective The aim of this study was to examine whether sevoflurane in oxygen was equivalent to near equipotent concentrations of nitrous oxide in oxygen when used as an inhalation sedation agent in terms of patient and user acceptability. Method Forty anxious dental patients referred to the sedation suite at Cardiff University School of Dentistry received either nitrous oxide to a maximum concentration of $40 \%$ or sevoflurane to a maximum concentration of $0.3 \%$ for a routine maxillary plastic restoration with articaine infiltration local analgesia. The inhalation sedation agent to be administered was chosen by a random number allocator. Measurements of blood pressure, oxygen saturation, heart rate, respiratory rate and bispectral index were recorded every 5 minutes. At the end of the treatment episode the patient, the operator and an observer who was unaware of the agent used, recorded their impressions about the episode by completing questionnaires. Results In the doses used in this study, sevoflurane was found to be as effective as an inhalation sedation agent as the standard dose of nitrous oxide used in normal inhalation sedation in the treatment of adult anxious dental patients. Conclusion Sevoflurane in low concentrations is equivalent in effect to near equipotent concentrations of nitrous oxide. This would suggest that further research, perhaps with slightly higher concentrations of sevoflurane, is needed. If sevoflurane was shown to be acceptable at slightly higher concentrations, there is scope to explore the development of equipment specifically designed to deliver sevoflurane as an inhalation sedation agent in future.
\end{abstract}

\section{INTRODUCTION}

Inhalation sedation is a conscious sedation technique used to manage anxiety that an individual dental patient can feel about dental treatment. During inhalation sedation a gaseous sedative is mixed with oxygen to provide relief of that anxiety. The commonest inhalational sedative agent used in the UK is nitrous oxide. Conscious sedation in the UK is defined as; 'a technique in which the use of a drug or drugs produces a state of depression of the central nervous system enabling treatment to be carried out, but during which verbal contact with the patient is maintained throughout the period of sedation. The drugs and techniques used to provide conscious sedation for dental

${ }^{1}$ Lecturer in Sedation and Special Care Dentistry, ${ }^{2}$ Reader in Sedation and Special Care Dentistry, School of Dentistry, College of Biomedical and Life Sciences, Cardiff University, Heath Park, Cardiff, CF14 4XY

*Correspondence to: Mick Allen

Email:AllenMK@cardiff.ac.uk

Online article number E18

Refereed Paper - accepted 20 May 2014

DOI: $10.1038 /$ sj.bdj.2014.998

${ }^{\circ}$ British Dental Journal 2014; 217: E18 treatment should carry a margin of safety wide enough to render loss of consciousness unlikely'. ${ }^{1-3}$ At present the inhalation sedation agent of choice is nitrous oxide. ${ }^{1-3}$ During inhalation sedation, nitrous oxide is incrementally introduced to the individual patient's response to produce a feeling of relaxation and anxiolysis. ${ }^{4}$

The success in managing dental anxiety using nitrous oxide inhalation sedation has been confirmed by many clinical studies. ${ }^{5-8}$ These studies examined the success of inhalation sedation in the management of paediatric dental cases. Successful completion of treatment was found to occur in around $84 \%$ of cases.

The use of nitrous oxide, however, is not without local and global environmental effects. Chronic exposure of medical and dental staff to nitrous oxide can lead to adverse effects. ${ }^{9,10}$ These adverse effects can be haematological, ${ }^{11,12}$ neurological, ${ }^{13}$ hepatorenal, ${ }^{9}$ reproductive ${ }^{14}$ and ophthalmological. ${ }^{15}$ Nitrous oxide is also a drug of misuse by dental professionals ${ }^{16}$ and in wider society. Globally nitrous oxide is a 'greenhouse gas' ${ }^{17}$ and in the atmosphere can combine with oxygen to produce the ozone depleting compound nitric oxide. ${ }^{18}$ It is good clinical governance to prevent unnecessary exposure of staff to nitrous oxide. In the UK, limits of exposure to staff form part of the Control of Substances Hazardous to Health Regulations (COSHH) in particular the Occupational exposure standards (OES) introduced in January $1996 .{ }^{19}$ Exposure of staff can be decreased by: efficient scavenging, suitable nosepieces, good technique to reduce mouth breathing and using well-ventilated rooms.

The increased appreciation of the difficulties associated with using nitrous oxide has led to the examination of alternative inhalation sedation agents (Table 1). The agents that have been examined are:

- Isoflurane $e^{20-22}$

- Xenon ${ }^{23,24}$

- Sevoflurane, both in isolation ${ }^{25-27}$ and with other drugs. ${ }^{28-30}$

From these studies it might be assumed that any of the above agents might be a suitable alternative to nitrous oxide. However, isoflurane ${ }^{31}$ is too irritant and pungent for patients to tolerate; xenon is 
extremely expensive ${ }^{23}$ and must be used via a rebreathing circuit; and sevoflurane, while expensive, lacks equipment dedicated for its use an inhalation sedation agent.

\section{OBJECTIVE}

Clinical trials are used to test the effectiveness of either a new drug, a new formulation of an existing drug or a new means of delivering a drug. Trials can be designed to establish if the effect on a particular outcome measure, perhaps a reduction in the level of cholesterol, is superior to the effect of a placebo. This is referred to as a 'placebo controlled trial'. However, it might be considered unethical to test a new drug against a placebo if an effective treatment for the particular outcome measure already exists. In a 'superiority trial' a new drug might be tested to see if it performs better than the existing therapy. In such trials a 'null hypothesis', that there is no difference between the drugs, is tested using an appropriate statistical test. The trial attempts to demonstrate that the hypothesis can be rejected, by showing a statistically significant difference. Failure to demonstrate a difference does not mean that the drugs are equivalent. Researchers may hope to demonstrate equivalence between a new drug and the standard therapy. The new drug may be cheaper or provide a second line treatment if, or when, the first line treatment has proved ineffective or poorly tolerated. It is not possible to demonstrate exact equivalence between two drugs but the aim of an equivalence trial is to demonstrate that any differences in a particular outcome lie within an accepted range known as the equivalence margin. It is crucial that equivalence trials follow exact methods to prevent false results being produced. ${ }^{32}$

In this equivalence trial, the aim was to explore if sevoflurane could be considered equivalent to nitrous oxide as an inhalation sedation agent for dental treatment in adults in terms of patient and user acceptability.

\section{MAIN OUTCOME MEASURES}

The outcome measures used to demonstrate equivalence were:

- Effectiveness of the sedative and anxiolytic effect for patients. This was measured using visual analogue scales and a post-operative questionnaire completed by the patient

- Apparent effectiveness of the sedative and anxiolytic effect on the patient recorded by an observer experienced in the management of patients undergoing inhalation sedation and who was blind to the type of agent used. This was recorded using visual analogue scales

- Apparent effectiveness of the sedative

Table 1 A comparison of the ideal inhalation sedation agent with nitrous oxide and sevoflurane

\begin{tabular}{l|l|l|l}
\hline Agent & Ideal & Sevoflurane & Nitrous oxide \\
\hline Anxiolysis & Yes & Yes & Yes \\
\hline Ease of titration & Yes & Yes & Yes \\
\hline Induction & Smooth and rapid & Smooth and rapid & Smooth and rapid \\
\hline Recovery & Rapid & Rapid & Rapid \\
\hline Cardio/respiratory stability & Yes & Yes & Yes \\
\hline Pungent and irritant to airway & No & No & No \\
\hline Toxicity & No & No & $\begin{array}{l}\text { Yes with prolonged or } \\
\text { chronic exposure }\end{array}$ \\
\hline Metabolism & $0 \%$ & $3 \%$ & Less than 1\% \\
\hline Blood gas solubility & Low & 0.69 & 0.47 \\
\hline Ease of altering depth of sedation & Rapid & Rapid & Rapid \\
\hline Environmental pollutant & No & No & Yes \\
\cline { 2 - 4 } & & & \\
\hline
\end{tabular}

and hypnotic effect on the patient and working conditions for an operator experienced in treating patients under inhalation sedation. This was recorded via sedation scores and behavioural characteristics scores

- Physiological measurement of blood pressure, oxygen saturation, pulse, respiratory rate and bispectral index at 5 minute intervals.

On statistical advice from colleagues at the Department of Anaesthetics, Intensive Care and Pain Medicine, the 95\% confidence interval was calculated for the difference in scores between the two groups of patients (one group receiving sevoflurane and the second group nitrous oxide). The primary outcome measure was the response to the question 'Did you find this form of sedation effective?', recorded on a $100 \mathrm{~mm}$ visual analogue scale. Assuming that a difference of less than $10 \mathrm{~mm}$ between the groups was unimportant, further calculations with a sample size of 20 patients in each group provided a confidence interval of -6.4 to $6.4 \mathrm{~mm}$ for no difference, much less than the acceptable $10 \mathrm{~mm}$.

\section{MATERIALS AND METHODS}

Ethical approval for the study was gained from The Cardiff and Vale NHS Trust Research and Development Office and Local Research Ethics Committee.

\section{Patient selection}

The study involved the provision of conscious sedation to anxious dental patients who had been referred by either a general dental practitioner (GDP), general medical practitioner (GMP) or community dental service practitioner to the sedation suite at Cardiff University School of Dentistry. The management strategies utilised in the sedation suite include the use of behavioural management techniques, hypnosis, inhalation sedation using nitrous oxide and oxygen, intravenous sedation using midazolam, oral sedation and intranasal sedation using midazolam. Intravenous sedation using propofol administered by a consultant anaesthetist is used in a separate area as part of an MSc module in conscious sedation. Patients referred to the sedation suite vary widely in their medical status. For safety and ethical reasons only patients who met the American Society of Anaesthesiologists (ASA) rating I were included in the study. Exclusion criteria were:

Unwillingness to participate in the study

- ASA II or greater

- Patients taking psychoactive medication

- Pregnancy

- Intellectual impairment that may have prevented the patient understanding the aim of the study and therefore not being able to give informed consent

- Inability to arrange an escorting adult

- Participating in other studies

- Anatomical anomalies such a nasal polyps preventing inhalation of gases

- Allergy to sevoflurane or other volatile gases

- Familial or personal history of malignant hyperthermia

- Patients who had previous experience of inhalation sedation.

Although the presence of an adult escort is not mandatory for inhalation sedation using nitrous oxide, it is a recommendation of the sedation suite that patients who have 
not experienced inhalation sedation should attend with an adult escort. To avoid the introduction of bias this recommendation was followed for both patient groups.

\section{Additional considerations}

Malignant hyperthermia is a fulminant, lifethreatening condition ${ }^{33}$ affecting between 1 in 5,000 and 1 in 200,000 of the population and is familial with a dominant pattern of inheritance. It is triggered by exposure to any of the volatile anaesthetic agents such as sevoflurane and all depolarising muscle relaxants. It is characterised by hypermetabolism, muscle rigidity, muscle injury and increased sympathetic nervous system activity. Because of this risk it was necessary to review the protocol regarding management of malignant hyperthermia ${ }^{34}$ with anaesthetic colleagues and to have a clear procedure in place should such an event occur.

\section{Study design}

The study comprised a stratified, randomised equivalence study of 40 adult patients referred to the sedation suite for dental treatment because of their dental anxiety. At their initial presentation for assessment patients were asked to complete a modified dental anxiety score (MDAS), ${ }^{35}$ a comprehensive medical history questionnaire and to answer questions about their social and dental history. Patients who required a plastic restoration in a maxillary tooth under infiltration local analgesia and inhalation sedation were selected for inclusion in the study. The rationale was that analgesia of maxillary teeth is less operator sensitive and more reproducible. The patient's blood pressure was recorded. Patients were given a full explanation of what the trial would involve. Patients were also given an information sheet about the trial to take home. This included the reassurance that should they choose to withdraw from the trial then their treatment would proceed without delay anyway. No patient opted to withdraw. Written informed consent was gained from the patient using the standard dental hospital consent form.

Sevoflurane cannot be delivered via the same dedicated machinery as nitrous oxide so a Boyle's anaesthetic machine was modified by the Clinical Engineering Department, Cardiff and Vale NHS Trust to deliver the sevoflurane. A possible complication of this was that the Boyle's machine could also deliver nitrous oxide mixed with sevoflurane. The machine was further modified to prevent the delivery of nitrous oxide in this way. The Boyle's machine was fitted with a Blease Datum anaesthetic vaporiser (Blease Datum,
Beech House, Chiltern Court, Ashridge Rd, Chesham, HP5 2PX, UK). The machine was calibrated using a gas analyser and the concentration dial on the vaporiser clearly marked at $0.3 \%$ sevoflurane.

MAC is the minimum alveolar concentration (in volumes per cent) of an anaesthetic gas at 1 atmosphere absolute that prevents movement of $50 \%$ of the population to a standard stimulus. ${ }^{36}$ The effectiveness of anaesthesia and sedation is related to the partial pressure of an inhalation agent in the brain, as opposed to its alveolar concentration. MAC, because it is measurable, is widely regarded as an index of anaesthetic potency. Sevoflurane is a potent agent with a MAC of $2.0 \%$ whereas nitrous oxide is a weak agent with a MAC of $110 \%$. Most inhalation sedation for dental treatment occurs at a concentration of nitrous oxide between 25 and 40\%. ${ }^{37}$ This would equate to a concentration of sevoflurane of $0.25 \%$ and $0.4 \%$. In order to maintain a wide margin of safety it was decided, with advice from anaesthetic colleagues, to limit the concentration of sevoflurane to $0.3 \%$ during the study.

\section{Use of bispectral index monitoring:}

Bispectral analysis (BIS) is a measure of the pharmacodynamic effects of anaesthesia and sedation on the central nervous system (CNS). ${ }^{38}$ The basis for BIS technology is the surface encephalogram that shows total brain activity as a waveform. This waveform varies during the use of sedatives and anaesthetics. The BIS index is derived from utilising a composite of multiple electroencephalography (EEG) signal processing techniques, including bispectral analysis and time domain analysis. Analysis by multivariate statistical models of EEG data from over 5,000 subjects who had received one or more of the most common hypnotic agents provided the database from which the BIS algorithm could be derived. From this a numerical figure was extrapolated and has been used as a parameter to measure the effects of sedation and anaesthesia. ${ }^{39,40}$ BIS values vary from 100 (fully awake) to 0 (flat line EEG), hence a lower BIS number would indicate reduced brain activity. From the way the BIS value is derived, it can be considered as a statistical function and as an indicator of very recent sedation. ${ }^{41}$ BIS monitoring was used during this trial to acquire additional data on each patient's response to the sedative administered.

Before each treatment session the study equipment would be set up and tested. The equipment comprised: a MDM Quantiflex nitrous oxide inhalation sedation apparatus; a modified Boyle's machine with a sample line to a gas analyser attached to ensure the correct dosage of sevoflurane; an ECG monitor; a pulse oximeter; an automatic sphygmomanometer and a BIS machine.

Screens were placed to obscure the machinery from the observer. The same observer was used for every patient seen, and the same dedicated sedation nurse assisted with each patient. When the reception staff had informed the operator of the patient's arrival a National Examining Board for Dental Nurses (NEBDN) sedation trained dental nurse would give the patient a MDAS questionnaire to complete and also a Gestalt test to perform. Gestalt is a psychological term used to describe an organised 'whole' as being greater than the sum of its parts. Gestalt tests can be used to measure recovery from anaesthesia. ${ }^{42}$

On attending the appointment the patient was asked if they were experiencing any discomfort away from the planned filling site and also if there had been any change in medical history. The planned procedure was confirmed, preoperative blood pressure taken and ECG leads attached. The patient was then reclined and the BIS and pulse oximeter leads attached. As the gas analyser made a very distinctive sound, it was turned on for every case to try and avoid bias. The type of agent used was allocated from a master list produced by a random number generator.

Inhalation sedation involves the use of 100\% oxygen for an initial 2 mins and then the incremental introduction of the sedative agent titrated to the patient's response. During the trial the actions involved in administering both the real agent and the actions involved in administering the alternative agent were performed so that the observer was unclear as to which agent was being used. Topical anaesthetic gel was applied to the local anaesthetic infiltration site for $1 \mathrm{~min}$ and then an infiltration of $2.2 \mathrm{ml} 4 \%$ articaine and 1:100,000 adrenaline was slowly given. After allowing 5 mins for full analgesia to take place the removal of caries and then restoration of the tooth was completed using conventional dental instruments and materials. On completion of treatment 100\% oxygen was administered for 4 mins to prevent possible diffusion hypoxia. The patient was asked to complete another Gestalt test and a post-operative questionnaire. Both the observer and the operator completed questionnaires. To avoid placing undue pressure on the patient the operator would place himself outside of the patient's direct line of vision while being able to still monitor his or her wellbeing. The completed questionnaires were collected and placed in a secured folder and locked in a cabinet. 


\section{RESULTS}

Forty patients completed the clinical trial. There were 18 male patients and 22 female patients with an average age of 34 years. The age range was 18 to 62 years. On completion of the study, the anonymised raw data was entered onto an Excel spreadsheet and passed for analysis to a statistician in the Department of Anaesthetics, Intensive Care and Pain Medicine of Cardiff University.

Analysis involved chi-squared analysis for all of the question and answer sections except answer seven, 'Do you remember being told the treatment was complete for today', which was analysed using Fischer's exact test because of low numbers. The results from the visual analogue scales were analysed using the Mann-Whitney U-test.

\section{DISCUSSION}

Analysis of the results showed that there was equivalence between nitrous oxide and sevoflurane in the domains examined in this trial (Tables 2-6). On reflection there is scope for further study in this area. Sevoflurane was used at a low-dose in this study and this could be increased in further studies, in conjunction with anaesthetic colleagues, while remaining well below the MAC of 2\%. Another possible area of future study could be the development of machinery dedicated to the delivery of sevoflurane as a dental inhalation sedation agent.

\section{CONCLUSION}

Forty patients who were recruited for treatment in the study completed their planned dental procedure, for many this was their first dental experience for some time due to their anxiety. The technique of administering nitrous oxide inhalation sedation was familiar to the operator and the supporting sedation qualified dental nurses. The technique of administering small percentages of sevoflurane was less easy but by no means difficult, although the use of the gas analyser meant an additional machine to monitor for the assisting dental nurse. In a clinical trial setting in a dental teaching hospital there were fewer time pressures at each treatment episode than would be the case in primary care and so the safe delivery of an agent such as sevoflurane, using nondedicated machinery, was achieved without any complications. The questionnaires were generally well received and only one patient failed to complete them adequately. The operator and observer both felt that the questions they were expected to answer were reasonable and within their sphere of experience. In a future study it would perhaps be better if the operator also had visual analogue scales to complete, as these proved

Table 2 Responses to MDAS, observer and patient VAS questionnaire (median [IOR] range)
\begin{tabular}{|l|l|l|l}
\hline & Nitrous oxide & Sevoflurane & P value \\
\hline Modified dental anxiety score & $\begin{array}{l}20[17 \text { to } 24] \\
(7 \text { to } 25)\end{array}$ & $\begin{array}{l}18[14 \text { to } 21] \\
(6 \text { to } 25)\end{array}$ & $p=0.14$ (NS) \\
\hline Degree of patient relaxation & $\begin{array}{l}84[57 \text { to } 88] \\
(7 \text { to } 95)\end{array}$ & $\begin{array}{l}80[67 \text { to } 86] \\
(45 \text { to } 92)\end{array}$ & $p=0.62$ (NS) \\
\hline Effectiveness of sedation & $\begin{array}{l}85[59 \text { to } 88] \\
(5 \text { to } 94)\end{array}$ & $\begin{array}{l}82[68 \text { to } 86] \\
(38 \text { to } 93)\end{array}$ & $p=0.64$ (NS) \\
\hline Degree of anxiety & $\begin{array}{l}81[56 \text { to } 85] \\
(1 \text { to } 93)\end{array}$ & $\begin{array}{l}79[66 \text { to } 84] \\
(42 \text { to } 87)\end{array}$ & $p=0.64$ (NS) \\
\hline Patient visual analogue scale 1 & $\begin{array}{l}79[59 \text { to } 92] \\
(18 \text { to } 99)\end{array}$ & $\begin{array}{l}72[46 \text { to } 92] \\
(9 \text { to } 100)\end{array}$ & $p=0.46$ (NS) \\
\hline Patient visual analogue scale 2 & $\begin{array}{l}88[51-95] \\
(0 \text { to } 100)\end{array}$ & $\begin{array}{l}84[66 \text { to } 94] \\
(12 \text { to } 100)\end{array}$ & $p=0.94$ (NS): \\
\hline
\end{tabular}

\begin{tabular}{|c|c|c|c|c|c|c|}
\hline Question & & Yes & No & Not sure & A little & Total \\
\hline \multirow{3}{*}{$\begin{array}{l}\text { Do you remember } \\
\text { having an injection }\end{array}$} & Nitrous oxide & $14(73.7 \%)$ & $2(10.5 \%)$ & $3(15.8 \%)$ & & 19 \\
\hline & Sevoflurane & $17(85.0 \%)$ & $2(10.0 \%)$ & $1(5.0 \%)$ & & 20 \\
\hline & Total & $31(79.4 \%)$ & $4(10.25 \%)$ & $4(10.25 \%)$ & & 39 \\
\hline \multirow{3}{*}{$\begin{array}{l}\text { Do you remember } \\
\text { the fast hand piece } \\
\text { being used? }\end{array}$} & Nitrous oxide & $9(47.4 \%)$ & $4(21.1 \%)$ & $6(31.6 \%)$ & & 19 \\
\hline & Sevoflurane & $13(65.0 \%)$ & $3(15.0 \%)$ & $4(20.0 \%)$ & & 20 \\
\hline & Total & $22(56.4 \%)$ & $7(17.95 \%)$ & $10(25.6 \%)$ & & 39 \\
\hline \multirow{3}{*}{ Did it bother you } & Nitrous oxide & $10(52.6 \%)$ & $2(10.5 \%)$ & & $7(36.8 \%)$ & 19 \\
\hline & Sevoflurane & $10(52.6 \%)$ & $0(0 \%)$ & & $9(47.4 \%)$ & 19 \\
\hline & Total & $20(52.6 \%)$ & $2(5.3 \%)$ & & $16(42.1 \%)$ & 38 \\
\hline \multirow{3}{*}{$\begin{array}{l}\text { Do you remember } \\
\text { the slow hand piece } \\
\text { being used? }\end{array}$} & Nitrous oxide & $12(63.2 \%)$ & $1(5.3 \%)$ & $6(31.6 \%)$ & & 19 \\
\hline & Sevoflurane & $15(75.0 \%)$ & $1(5.0 \%)$ & $4(20.0 \%)$ & & 20 \\
\hline & Total & $27(69.2 \%)$ & $2(5.1 \%)$ & $10(25.6 \%)$ & & 39 \\
\hline \multirow{3}{*}{ Did it bother you? } & Nitrous oxide & $10(52.6 \%)$ & $1(5.3 \%)$ & & $8(42.1 \%)$ & 19 \\
\hline & Sevoflurane & $12(60.0 \%)$ & $1(5.0 \%)$ & & 7 (35.0\%) & 20 \\
\hline & Total & $22(56.4 \%)$ & $2(5.1 \%)$ & & $15(38.5 \%)$ & 39 \\
\hline \multirow{3}{*}{$\begin{array}{l}\text { Do you remember a } \\
\text { filling being placed } \\
\text { in your tooth }\end{array}$} & Nitrous oxide & $14(73.7 \%)$ & $2(10.5 \%)$ & $3(15.8 \%)$ & & 19 \\
\hline & Sevoflurane & 18(90.0\%) & $2(10.0 \%)$ & 0 & & 20 \\
\hline & Total & $32(82.1 \%)$ & $4(10.3 \%)$ & $3(7.7 \%)$ & & 39 \\
\hline \multirow{3}{*}{$\begin{array}{l}\text { Do you remember } \\
\text { being told that } \\
\text { treatment is } \\
\text { complete for today? }\end{array}$} & Nitrous oxide & $19(95 \%)$ & $1(5 \%)$ & & & 20 \\
\hline & Sevoflurane & $20(100 \%)$ & 0 & & & 20 \\
\hline & Total & $39(97.5)$ & $1(2.5 \%)$ & & & 40 \\
\hline \multirow{3}{*}{$\begin{array}{l}\text { Do you remember } \\
\text { if the gas smelled? }\end{array}$} & Nitrous oxide & $6(30.0 \%)$ & $8(40.0 \%)$ & $6(30.0 \%)$ & & 20 \\
\hline & Sevoflurane & $15(75.0 \%)$ & $5(25.0 \%)$ & 0 & & 20 \\
\hline & Total & $21(52.5 \%)$ & $13(32.5 \%)$ & $6(15.0 \%)$ & & 40 \\
\hline \multirow{3}{*}{$\begin{array}{l}\text { Was it pleasant } \\
\text { or not?" }\end{array}$} & Nitrous oxide & $6(30.0 \%)$ & $1(5.0 \%)$ & $13(65.0 \%)$ & & 20 \\
\hline & Sevoflurane & $10(50.0 \%)$ & 4 (20.0\%) & $6(30.0 \%)$ & & 20 \\
\hline & Total & $16(40.0 \%)$ & $5(12.5 \%)$ & $19(47.5 \%)$ & & 40 \\
\hline
\end{tabular}

to be a very valuable tool for recording subjective experiences. In a trial such as this the use of the Trieger test to assess recovery from conscious sedation might be regarded as being excessive but because of the lack of experience in using sevoflurane it was considered prudent to be able to assess recovery at the end of the treatment session. 


\begin{tabular}{|c|c|c|c|c|c|c|c|c|c|c|c|c|c|c|c|c|c|c|c|c|c|}
\hline Patient & 1 & 3 & 5 & 8 & 9 & 13 & 14 & 15 & 17 & 18 & 19 & 23 & 26 & 30 & 31 & 32 & 34 & 35 & 36 & 37 & 40 \\
\hline \% Sevoflurane & 0.3 & 0.2 & 40 & 0.3 & 0.3 & 0.3 & 0.2 & 0.3 & 0.1 & 0.3 & 0.3 & 0.2 & 0.3 & 0.3 & 0.3 & 0.3 & 0.3 & 0.3 & 0.3 & 0.2 & 0.3 \\
\hline $\begin{array}{l}\text { Modified dental anxiety } \\
\text { score }\end{array}$ & 13 & 18 & 21 & 20 & 17 & 9 & 21 & 18 & 18 & 20 & 21 & 18 & 23 & 13 & 6 & 25 & 19 & 19 & 22 & 13 & 17 \\
\hline Sedation score & 1 & 2 & 2 & 1 & 1 & 2 & 2 & 2 & 2 & 1 & 2 & 1 & 2 & 2 & 1 & 2 & 1 & 1 & 2 & 2 & 1 \\
\hline Ellis score & 1 & 2 & 1 & 2 & 1 & 1 & 1 & 1 & 1 & 1 & 1 & 1 & 2 & 2 & 1 & 1 & 2 & 1 & 1 & 1 & 4 \\
\hline $\begin{array}{l}\text { Reproduced Trieger } \\
\text { test at end }\end{array}$ & Yes & Yes & Yes & Yes & Yes & Yes & Yes & Yes & Yes & Yes & Yes & Yes & Yes & Yes & Yes & Yes & Yes & Yes & Yes & Yes & Yes \\
\hline Maximum systolic BP & 148 & 127 & 125 & 145 & 119 & 136 & 122 & 133 & 144 & 140 & 126 & 156 & 143 & 117 & 134 & 108 & 119 & 135 & 149 & 137 & 124 \\
\hline Maximum diastolic BP & 97 & 63 & 61 & 88 & 56 & 71 & 58 & 80 & 78 & 75 & 66 & 91 & 58 & 62 & 78 & 58 & 62 & 72 & 83 & 70 & 74 \\
\hline Minimum systolic BP & 130 & 105 & 112 & 134 & 85 & 129 & 108 & 111 & 116 & 122 & 94 & 147 & 124 & 102 & 124 & 100 & 110 & 114 & 129 & 119 & 101 \\
\hline Minimum diastolic BP & 70. & 55. & 40 & 66 & 23 & 64 & 45 & 62 & 59 & 54 & 54 & 74 & 58 & 46 & 59 & 45 & 48 & 45 & 66 & 54 & 48 \\
\hline $\begin{array}{l}\text { Maximum respiratory rate } \\
\text { (breaths/min) }\end{array}$ & 14 & 17 & 23 & 24 & 20 & 22 & 23 & 19 & 26 & 31 & 23 & 24 & 22 & 21 & 28 & 17 & 27 & 24 & 19 & 27 & 14 \\
\hline $\begin{array}{l}\text { Minimum respiratory rate } \\
\text { (breaths/min) }\end{array}$ & 8 & 9 & 12 & 10 & 16 & 13 & 10 & 12 & 16 & 12 & 17 & 14 & 12 & 11 & 11 & 11 & 15 & 14 & 13 & 14 & 8 \\
\hline $\begin{array}{l}\text { Minimum oxygen saturation } \\
(\%)\end{array}$ & 97 & 100 & 100 & 100 & 100 & 100 & 100 & 100 & 97 & 97 & 100 & 100 & 99 & 100 & 98 & 100 & 100 & 100 & 100 & 99 & 100 \\
\hline Maximum heart rate & 87 & 87 & 99 & 76 & 109 & 67 & 80 & 107 & 104 & 96 & 89 & 103 & 86 & 82 & 108 & 86 & 76 & 79 & 98 & 76 & 76 \\
\hline Minimum heart rate & 71 & 71 & 63 & 66 & 82 & 53 & 62 & 93 & 84 & 74 & 73 & 95 & 64 & 57 & 80 & 72 & 56 & 64 & 84 & 59 & 63 \\
\hline Minimum BIS reading & 96 & 97 & 84 & 97 & 96 & 90 & 96 & 97 & 97 & 90 & 98 & 97 & 96 & 93 & 83 & 98 & 91 & 88 & 97 & 95 & 97 \\
\hline
\end{tabular}

\section{Table 5 Physiological results for patients given nitrous oxide}

\begin{tabular}{|c|c|c|c|c|c|c|c|c|c|c|c|c|c|c|c|c|c|c|c|}
\hline Patient & 2 & 4 & 6 & 7 & 10 & 11 & 12 & 16 & 20 & 21 & 22 & 24 & 25 & 27 & 28 & 29 & 33 & 38 & 39 \\
\hline Nitrous oxide\% & 30 & 35 & 30 & 40 & 40 & 35 & 30 & 40 & 30 & 40 & 30 & 35 & 30 & 40 & 35 & 35 & 35 & 35 & 35 \\
\hline $\begin{array}{l}\text { Modified dental anxiety } \\
\text { score }\end{array}$ & 23 & 19 & 24 & 23 & 25 & 17 & 9 & 15 & 24 & 24 & 23 & 19 & 14 & 19 & 7 & 20 & 25 & 18 & 18 \\
\hline Sedation score & 1 & 3 & 2 & 1 & 1 & 2 & 2 & 2 & 2 & 1 & 1 & 1 & 2 & 1 & 2 & 1 & 2 & 1 & 1 \\
\hline Ellis score & 2 & 2 & 2 & 3 & 1 & 2 & 1 & 1 & 1 & 3 & 1 & 1 & 1 & 2 & 1 & 2 & 1 & 1 & 1 \\
\hline $\begin{array}{l}\text { Reproduced Trieger test } \\
\text { at end }\end{array}$ & Yes & Yes & Yes & Yes & Yes & Yes & Yes & Yes & Yes & Yes & Yes & Yes & Yes & Yes & Yes & Yes & Yes & Yes & Yes \\
\hline Maximum systolic BP & 139 & 133 & 104 & 149 & 122 & 163 & 114 & 125 & 130 & 143 & 109 & 107 & 122 & 119 & 131 & 131 & 156 & 135 & 101 \\
\hline Maximum diastolic BP & 80 & 69 & 88 & 83 & 73 & 84 & 66 & 79 & 68 & 75 & 59 & 59 & 63 & 72 & 63 & 68 & 77 & 81 & 52 \\
\hline Minimum systolic BP & 120 & 114 & 93 & 125 & 110 & 136 & 102 & 115 & 119 & 121 & 99 & 99 & 110 & 107 & 123 & 119 & 135 & 117 & 89 \\
\hline Minimum diastolic BP & 72. & 44. & 50 & 61 & 52 & 72 & 47 & 57 & 56 & 57 & 48 & 54 & 53 & 38 & 47 & 54 & 61 & 63 & 44 \\
\hline $\begin{array}{l}\text { Maximum respiratory rate } \\
\text { (breaths/min) }\end{array}$ & 17 & 15 & 20 & 25 & 16 & 20 & 20 & 16 & 52 & 24 & 18 & 24 & 24 & * & 21 & 24 & 17 & 18 & 21 \\
\hline $\begin{array}{l}\text { Minimum respiratory rate } \\
\text { (breaths/min) }\end{array}$ & 13 & 9 & 14 & 20 & 9 & 18 & 10 & 13 & 17 & 16 & 16 & 15 & 15 & * & 12 & 13 & 10 & 13 & 13 \\
\hline $\begin{array}{l}\text { Minimum oxygen } \\
\text { saturation }\end{array}$ & 97 & 100 & 99 & 100 & 97 & 100 & 99 & 100 & 100 & 100 & 98 & 100 & 100 & 100 & 100 & 99 & 99 & 99 & 100 \\
\hline Maximum heart rate & 89 & 87 & 56 & 83 & 87 & 120 & 60 & 82 & 58 & 129 & 88 & 72 & 66 & 89 & 78 & 76 & 100 & 79 & 90 \\
\hline Minimum heart rate & 74 & 71 & 46 & 71 & 72 & 89 & 49 & 65 & 49 & 94 & 73 & 60 & 48 & 57 & 59 & 54 & 86 & 70 & 64 \\
\hline Minimum BIS reading & 98 & 97 & 92 & 95 & 98 & 97 & 92 & 96 & 96 & 98 & 92 & 95 & 88 & 98 & 85 & 97 & 96 & 97 & 95 \\
\hline
\end{tabular}

The selection criteria for this type of study had to be rigid and correctly applied to avoid introducing any bias. During screening of patients to try and find a suitable participant it was not uncommon to see 10 or 12 patients before anyone who fitted the criteria was examined. For the operator, who was a parttime student working mostly in primary care, this proved worryingly time consuming. Fortunately, many patients appreciated that they were attending a dental teaching hospital and that participation in a study 


\begin{tabular}{|c|c|c|c|}
\hline Variable & Group & Median [IQR] (range) & $\begin{array}{l}\text { P value } \\
\text { (Mann-Whitney U } \\
\text { test) }\end{array}$ \\
\hline \multirow{2}{*}{ BIS min } & nitrous oxide & 96 [92 to 97 ] (84 to 98 ) & \multirow{2}{*}{0.81} \\
\hline & sevoflurane & 96 [92 to 97 ] (83 to 98 ) & \\
\hline \multirow{2}{*}{ DY MAX } & nitrous oxide & 71 [63 to 80 ] (52 to 88 ) & \multirow{2}{*}{0.98} \\
\hline & sevoflurane & 72 [62 to 80 ] (56 to 97$)$ & \\
\hline \multirow{2}{*}{ DY MIN } & nitrous oxide & 54 [47 to 60 ] (38 to 72$)$ & \multirow{2}{*}{0.45} \\
\hline & sevoflurane & 55 [47 to 64 ] (23 to 74$)$ & \\
\hline \multirow{2}{*}{ MAX HR } & nitrous oxide & 85 [73 to 97 ] (56 to 129) & \multirow{2}{*}{0.52} \\
\hline & sevoflurane & 87 [77 to 102$]$ (67 to 109 ) & \\
\hline \multirow{2}{*}{ MIN HR } & nitrous oxide & 65 [55 to 74 ] (46 to 94$)$ & \multirow{2}{*}{0.24} \\
\hline & sevoflurane & 71 [62 to 82 ] (53 to 95$)$ & \\
\hline \multirow{2}{*}{ RESPMAX } & nitrous oxide & 20 [17 to 24 ] (15 to 52$)$ & \multirow{2}{*}{0.32} \\
\hline & sevoflurane & 23 [19 to 26 ] (14 to 31$)$ & \\
\hline \multirow{2}{*}{ RESPMIN } & nitrous oxide & 13 [12 to 16$]$ (9 to 20 ) & \multirow{2}{*}{0.20} \\
\hline & sevoflurane & 12 [10 to 14$]$ (8 to 17 ) & \\
\hline \multirow{2}{*}{ SPO2 MIN } & nitrous oxide & 100 [99 to 100] (97 to 100) & \multirow{2}{*}{0.52} \\
\hline & sevoflurane & 100 [99 to 100] (97 to 100) & \\
\hline \multirow{2}{*}{ SYS MAX } & nitrous oxide & 128 [115 to 138 ] (101 to 163$)$ & \multirow{2}{*}{0.22} \\
\hline & sevoflurane & 135 [123 to 144$]$ ( 108 to 156$)$ & \\
\hline \multirow{2}{*}{ SYS MIN } & nitrous oxide & 115 [103 to 121$]$ (89 to 136$)$ & \multirow{2}{*}{0.66} \\
\hline & sevoflurane & 115 [103 to 128 ] (85 to 147 ) & \\
\hline
\end{tabular}

such as this was to be expected and so once the process was explained only two patients declined to take part.

Patients who took part in the study were accepting of the monitoring and recording equipment used and many were interested in what the equipment was there to do. This distraction provided a useful way of introducing the patient into the treatment session.

In summary, the statistical analysis and experience gained within the limits of the study showed that sevoflurane was equivalent to nitrous oxide when administered at low doses for inhalation sedation in this study.

The authors would like to thank Professor Judith Hall, Head of Department of Anaesthetics, Intensive Care and Pain Medicine School of Medicine, Cardiff University, Cardiff and Dr Antony Wilkes, Senior Lecturer, Department of Anaesthetics, Intensive Care and Pain Medicine, School of Medicine, Cardiff University, Cardiff.

1. General Dental Council. Maintaining standards: Guidance to dentists on professional and personal conduct. London: GDC, 2001.

2. Department of Health. Conscious sedation in the provision of dental care. London: DH, 2003.

3. National Dental Advisory Committee for Scotland. Conscious sedation in dentistry. Edinburgh. National Dental Advisory Committee for Scotland, 2006

4. Meechan R, Robb N, Seymour R. Pain and anxiety control in dentistry. Oxford: Oxford University Press, 1999.

5. Shaw A, Meechan J, Kilpatrick N, Welbury R. The use of inhalation and local anaesthetic instead of general anaesthesia for extractions and minor oral surgery in children: A prospective study. Int J Paediatr Dent 1996; 53: 213-215.
6. Blain $\mathrm{K}$, Hill F. The use of inhalation sedation and local anaesthetic as an alternative to general anaesthesia for dental extractions in children. $\mathrm{Br}$ Dent J 1998; 12: 608-611.

7. Berge TI. Acceptance and side effects of nitrous oxide oxygen sedation for oral surgery procedures. Acta Odontol Scand 1999; 57: 201-206.

8. Bryan R. The success of inhalation sedation for comprehensive dental care within the Community Dental Service. Int J Paediatr Dent 2002; 12: 410-414.

9. Cohen E N, Gift H C, Brown B W et al. Occupational disease in dentistry and chronic exposure to trace anaesthetic gases. J Am Dent Assoc 1980; 101: 21-31.

10. Whitcher C, Cohen E, Trudell J. Chronic exposure to anaesthetic gases in the operating room. Anaesthesiology 1971; 35: 348-353.

11. Nunn J F. Clinical aspects of the interaction between nitrous oxide and vitamin B12. Br J Anaesth 1987; 59: 3-13.

12. Shaw A, Morgan M. Nitrous oxide: time to stop laughing? Anaesthesia 1998; 53: 213-215

13. Layzer R. Myeloneuropathy after prolonged exposure to nitrous oxide. Lancet 1978; 2: 1227.

14. Roland A S, Baird D D, Shore D L, Weinberg C R, Savitz D A, Wilcox A J. Nitrous oxide and spontaneous abortion in female dental assistants. Am J Epidemiol 1995: 141: 531-538.

15. Lockwood A, Yang F. Nitrous oxide inhalation anaesthesia in the presence of intraocular gas can cause irreversible blindness. Br Dent J 2008; 204: 247-248

16. Brilliant J. Nitrous oxide as a psychedelic drug. New Engl J Med 1970; 283: 1522

17. Maskell K, Callander B, Mintzer I. Basic science of climate change. Lancet 1993; 342: 1027-1031.

18. Logan M, Farmer J. Anaesthesia and the ozone layer. BrJ Anaesth 1989; 63: 645-647.

19. Health Services Advisory Committee. Anaesthetic gases: controlling exposure under COSHH. London: HMSO 1995

20. Parbrook G D, James J, Braid D P. Inhalation sedation with isoflurane: an alternative to nitrous oxide. $\mathrm{Br}$
Dent J 1987; 163: 88-92.

21. Mc Menemin M, Parbrook G. Comparison of the effects of sub anaesthetic concentration of isoflurane or nitrous oxide in volunteers. $\mathrm{Br}$ Anaesth 1988; 60: 56-63.

22. Ho E, Parbrook G, Still D, Parbrook E. Memory function after IV midazolam or inhalation of isoflurane for sedation during dental surgery. $\mathrm{Br} J$ Anaesth 1990; 64: 337-340.

23. Dingley J, King R, Hughes L et al. Exploration of xenon as a potential cardiostable sedative: a comparison with propofol after cardiac surgery. Anaesthesia 2001; 56: 826-835.

24. Bedi A, McCarroll C, Murray J M, Stevenson M A, Fee $J P$. The effects of subanaesthetic concentrations of xenon in volunteers. Anaesthesia 2002; 57: 233-241.

25. Tomi K, Mashimo T, Tashiro C et al. Alterations in pain threshold and psychomotor response associated with subanaesthetic concentrations of inhalation anaesthetics in humans. Br J Anaesth 1993; 70: 684-686.

26. Haraguchi $N$, Furusawa $H$, Takezaki R, Oi K. Inhalation sedation with sevoflurane: a comparative study with nitrous oxide. J Oral Maxillofac Surg 1995; 53: 24-26.

27. Carpenter $R$, Descamps M, Morley $C$, Leary $T$, Jones J. The effect of low dose sevoflurane on saccadic eye movement latency. Anaesthesia 2002; 57: 855-859.

28. Lahoud G, Averley P, Hanlon M. Sevoflurane inhalation conscious sedation for children having dental treatment. Anaesthesia 2001; 56: 447-484.

29. Lahoud G, Averley P. Comparison of sevoflurane and nitrous oxide mixture with nitrous oxide alone for inhalation conscious sedation in children having dental treatment: a randomized controlled trial. Anaesthesia 2002; 57: 446-450.

30. Averley P, Girdler N, Bond S, Steen N, Steele J. A randomised controlled trial of paediatric conscious sedation for dental treatment using intravenous midazolam combined with inhaled nitrous oxide or nitrous oxide/sevoflurane. Anaesthesia 2004; 591: 844-852.

31. McLeod D D, Ramayya G P, Tunstall M E. Selfadministered isoflurane in labour. A comparative study with entonox. Anaesthesia 1985; 60: 56-63.

32. Jones $B$, Jarvis $P$, Lewis J, Ebbutt $A$. Trials to assess equivalence: the importance of rigorous methods. BMJ 1996; 313: 36-39.

33. Denborough $M$, Forster J, Lovell $R$, Maplestone $P$, Villiers J. Anaesthetic deaths in a family. Br J Anaesth 1962; 34: 395-396.

34. Gemmell L. Management of a malignant hyperthermia crisis. Anaesthesia News 2011; 289: 27.

35. Humphris $\mathrm{G} M$, Clarke $H \mathrm{M}$, Freeman R. Does completing a dental anxiety questionnaire increase dental anxiety? A randomised controlled trial with adults in dental practice. Br Dent J 2006; 201: 33-35.

36. Aitkenhead A, Rowbotham D, Smith G (eds). Textbook of anaesthesia. 4th ed. London: Churchill Livingston, 2001.

37. Roberts G J. Inhalation sedation (relative analgesia) with oxygen/nitrous oxide gas mixtures: 1 . Principles. Dent Update 1990; 17: 139-142. 145-146.

38. Company overview of Aspects Medical Systems Inc, One Upland road, Norwood, MA 02062 USA Bloomberg Businessweek, 2014. Online overview available at http://investing.businessweek. com/research/stocks/private/snapshot. asp?privcapld=25134 (accessed June 2014).

39. Katoh T, Suzuki A, Ikeda K. Electroencephalographic derivatives as a tool for predicting depth of anaesthesia induced by sevoflurane. Anaesthesiology 1998; 88: 642-650.

40. Hall D L, Weaver J, Ganzberg, Rashid R, Wilson S. Bispectral EEG index monitoring of high-dose nitrous oxide and low-dose sevoflurane sedation. Anaesth Prog 2002; 49: 56-62.

41. Chan M T, Gin T. What does the Bispectral EEG index monitor? Eur J Anaethesio/ 2000; 17: 146-148.

42. Newman M G, Trieger N, Miller J C. Measuring recovery from anaesthesia-a simple test. Anaesth Analg 1969; 48: 136-140. 